NEW YORK-Idexx (Portland, ME) is perhaps the first U.S. agricultural biotechnology company to turn a profit, taking home $\$ 3.2$ million last year, according to Bio/Technology's survey of 1991 agbiotech earnings (table). Overall, though, the agbiotech sector lost money last year, with 10 surveyed companies losing $\$ 65$ million, or $\$ 6.5$ million apiece, on average. This compares unfavorably with 10 surveyed pesticide and seed companies that reported profits of $\$ 5.3$ billion in 1991, or an average of $\$ 530$ million each. DuPont (Wilmington, DE) was the leader among these companies, taking home $\$ 1.4$ billion last year.

Agbiotech firms increased their sales in 1991. The 10 surveyed companies brought in $\$ 124.7$ million last year, which averaged out to $\$ 12.5$ million a company, a 2.3 percent increase over 1990. Idexx-a maker of biodetectors for animal health, food, and biomedical applications-led the pack, with 1991 sales of $\$ 30.5$ million. Calgene (Davis, CA) came in second, amassing \$26.1 million in sales last year of cotton seeds, canola seeds, and canola oil.
The 10 pesticide and seed companies, for their part, saw sales drop 0.2 percent last year, compared to 1990 . Total sales came to $\$ 117$ billion in 1991 , for an average of $\$ 11.7$ billion a company. As with profits, DuPont led the way, with $\$ 38.7$ billion in 1991 sales.

Among agbiotech companies, Ecogen (Langhorne, PA) showed the biggest sales increase last year, a 244 percent jump from 1990. Initiation of a fouryear, \$12.7-million research and marketing agreement with Roussel-Uclaf (Paris) accounted for the increase, as did rising sales of Ecogen's Bacillus thuringiensis-based bioinsecticides. (The Bio/Technology survey included all operating revenues in its sales definition.) Runner-up Mycogen's (San Diego, CA) sales rose 71 percent last year, compared to 1990. Its acquisition of Soilserv-a provider of customized crop protection with annual sales of $\$ 22$ million-made up the increase. Pioneer Hi-Bred International (Des Moines, IL) led the pesticide and seed companies, with a 17 percent sales increase from 1990 to 1991.

-B.J. Spalding \& Bruce Shriver, Jr.
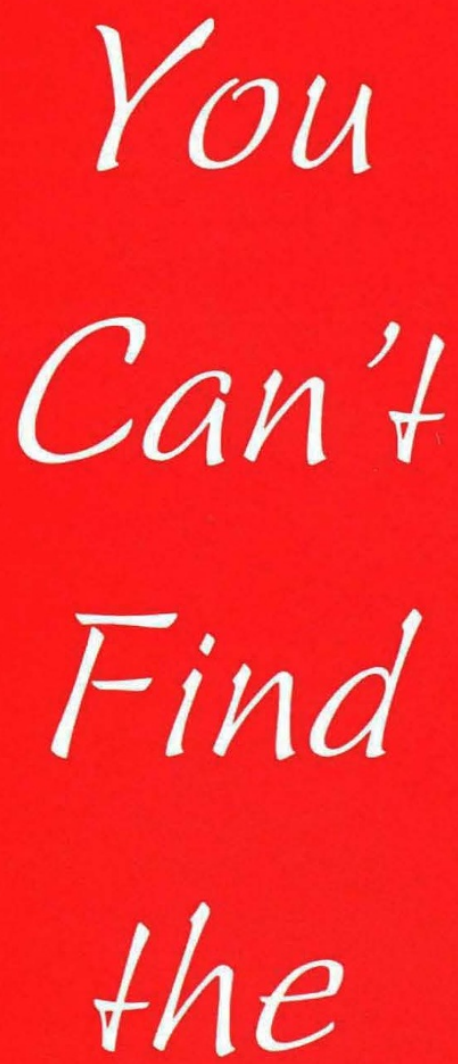

\section{AGBIO COMPANIES}

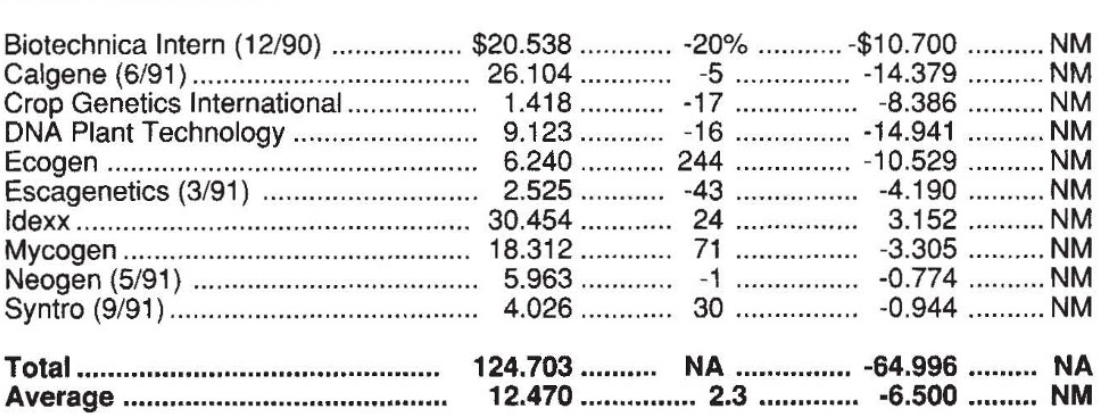

\section{PESTICIDE AND SEED COMPANIES}

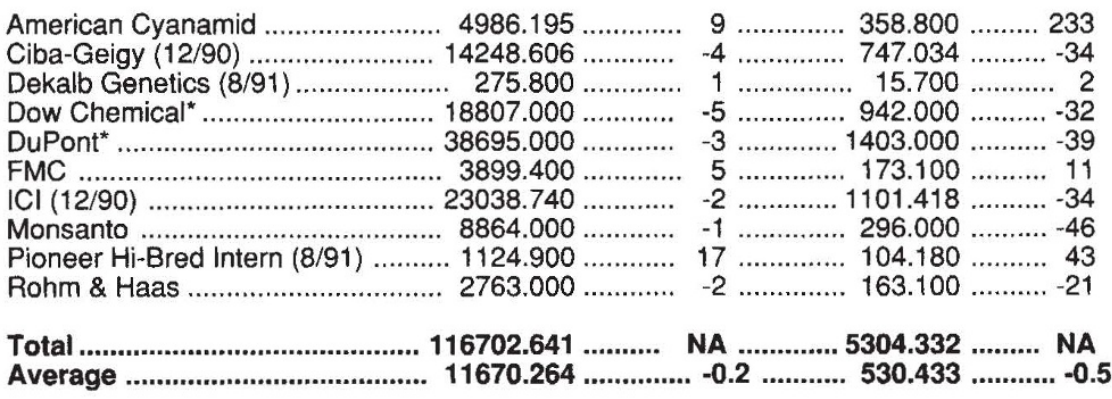

Sales include all sales and other operating revenues. Profits include net income from continuing operations before extraordinary items. Results are for the fiscal year ending 12/91, except as noted. *Sales include other income. NM means not meaningful. NA means not available.

Source: Standard \& Poor's Compustat Services (Englewood, CO)
SALES

$\begin{array}{rr}\text { Latest FY } & \text { Change } \\ \text { (\$ Millions) } & \text { From Last }\end{array}$

PROFITS

Latest FY Change

FY $(\%)$

$$
\text { FY (\%) }
$$

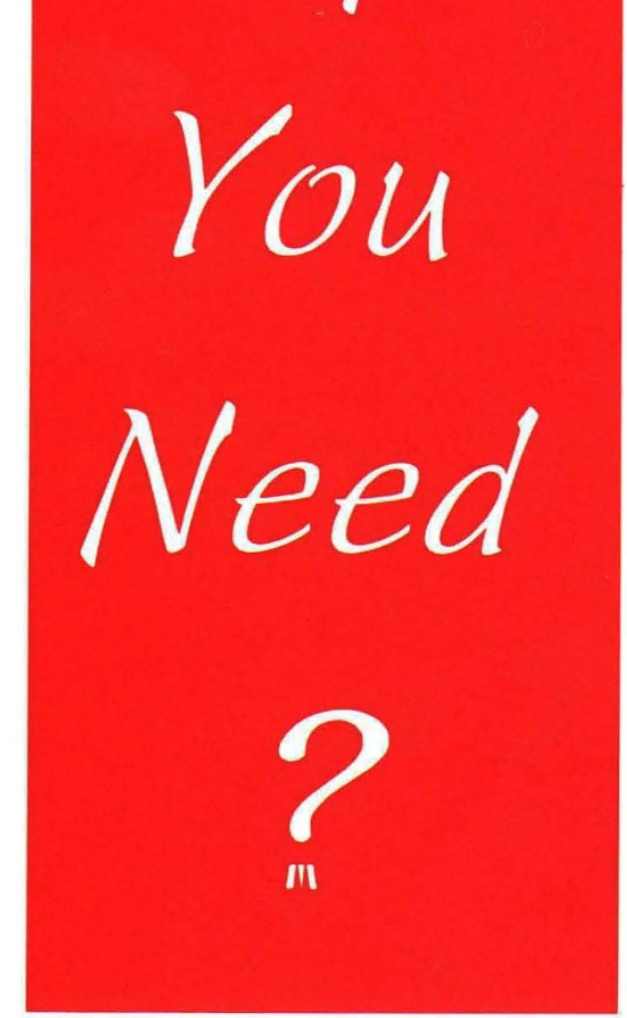

